\title{
Comunicarse escriblando en las redes
}

Communicating by writing on the networks

\section{Elixabete Pérez Gaztelu, Universidad de Deusto - elixabete.perez@deusto.es}

Esther Zulaika ljurko, Universidad de Deusto - esther.zulaika@deusto.es

Resumen

El objetivo de la comunicación es describir y sistematizar las características semiológicas del código escrito utilizado por jóvenes vascoparlantes en ámbitos lingüístico-comunicativos informales y, en particular, en conversaciones de las redes sociales. Dichas redes constituyen un espacio de comunicación privilegiado para detectar e investigar la innovación lingüística en la comunicación. Más, si cabe, si el objeto a investigar es el uso de una lengua como el euskera, que carece de descripciones de estas características. Se partirá de la hipótesis de que los jóvenes vascos aplican sus competencias comunicativas adecuándolas a la actuación comunicativa real, en función del objetivo, relación entre los participantes, ámbito, canal y otros factores que determinan la propia actividad comunicativa real y efectiva. Se analizará la convivencia e interacción de códigos y variedades lingüísticas que confluyen en esa actividad comunicativa. En definitiva, se intentará mostrar que el código de comunicación escrita de los jóvenes vascoparlantes usuarios de redes sociales (distinto del utilizado en comunicaciones formales) no es una mezcla asistemática e improvisada de diferentes códigos lingüísticos, sino que se asienta en unas bases sistemáticas compartidas. Y que todo ello constituye un nuevo espacio de comunicación en el que los jóvenes vascoparlantes tienen su lugar.

\section{Palabras clave}

Competencias comunicativas - redes sociales - códigos y variedades lingüísticas - espacio informal de comunicación.

\section{Abstract}

The aim of this paper is to describe and systematise the semiological characteristics of the written code used by young Basque speakers in informal linguistic-communicative environments and, in particular, in conversations on social networks. These networks constitute a privileged communication space for detecting and investigating linguistic innovation in communication. Even more so, if the object to be investigated is the use of a language such as Basque, which lacks descriptions of these characteristics. We will start from the hypothesis that young Basques apply their communicative competences adapting them to the real communicative performance, depending on the objective, relationship between the participants, sphere, channel and other factors that determine the real and effective communicative activity itself. The coexistence and interaction of codes and linguistic varieties that converge in this communicative activity will be analysed. In short, we will try to show that the written communication code of young Basque-speaking users of social networks (different from that used in formal communications) is not an asystematic and improvised mixture of different linguistic codes, but is based on shared systematic bases. And that all this constitutes a new communication space in which young Basque speakers have their place. 


\section{Objetivo}

El objetivo de esta comunicación es describir y sistematizar algunas de las características semiológicas del código escrito utilizado por jóvenes vascoparlantes en ámbitos lingüístico- comunicativos informales y, en particular, en conversaciones de las redes sociales. Dichas redes constituyen un espacio de comunicación privilegiado para detectar e investigar la innovación lingüística en la comunicación.

\section{Competencias comunicativas: comunicación escrita}

Esta comunicación se enmarca en la línea de investigación de las competencias comunicativas que está desarrollando el equipo; en las competencias de comunicación escrita y, en especial, las de los jóvenes y adolescentes vascos. En el proyecto anterior -basado en una amplia muestra de comunicaciones escritas de jóvenes de $1^{\circ}$ de bachillerato de centros de enseñanza de Gipuzkoa-, analizamos las competencias de comunicación escrita de los jóvenes en el ámbito comunicativo académico. (Perez Gaztelu, E; Zulaika, E., 2012; Perez Gaztelu, Zulaika, Muñoa, 2011).

Ahora abordaremos otro ámbito comunicativo de la juventud vasca: el de la comunicación escrita de carácter interpersonal e informal. Evidentemente, esto significa que deberemos tener en cuenta elementos, factores, estrategias, procesos distintos a los tenidos en cuenta al investigar comunicación escrita de carácter formal, académico.

En primer lugar, la relación que se establece entre los participantes en el proceso comunicativo (la distancia social Escandell, 2005) es crucial. En la investigación concluida la relación no era horizontal, simétrica: el autor del escrito, el emisor, era el estudiante y el destinatario (y receptor) el profesor. Los objetivos del proceso comunicativo (convencer al profesor de los conocimientos, competencias, habilidades...de uno mismo para lograr una buena calificación), tampoco eran los mismos que analizamos ahora, ni la situación, ni el medio (factor decisivo en los procesos comunicativos que analizamos), ni, en definitiva las características de la señal, del texto producido. Todo ello condiciona e incluso determina la comunicación, y por ello, al analizarla, ha de tenerse en cuenta.

Expresado al modo de los defensores de la existencia de un continuum de la tipología textual, hemos pasado de la investigación de los textos formales, planificados, corregidos... a los más "libres", a los inmediatos, improvisados.

Comunicarse coloquialmente, comunicarse escribiendo...; es decir, comunicarse a través de las TIC. Aun la observación más superficial muestra que cuando los jóvenes se comunican entre sí por escrito (casi) exclusivamente lo hacen a través de Internet, sea utilizando el ordenador, el teléfono o cualquier otro dispositivo con acceso a Internet. Esto no acarrea, sin embargo, que limiten el uso de Internet exclusivamente para comunicarse coloquialmente entre ellos; Internet es un espacio donde tienen cabida muchos tipos de comunicación muchos tipos de relaciones entre copartícipes, muchos tipos de textos escritos (blogs, listas de distribución, mensajes electrónicos, mensajes públicos de las redes sociales...) (Zamorano et al., 2004)... No obstante, insistimos en que, a nuestro modo de ver, no tiene sentido hablar de comunicación escrita coloquial entre jóvenes sin tener presentes las TIC e Internet. Y ese es precisamente nuestro objeto de estudio: la comunicación escrita1 informal producida, emitida, "mediada" por Internet (Briz y Serra, 1997; López Quero, 2003 $2010 \ldots)$.

Hemos elegido la conversación como género textual; las conversaciones escritas virtuales, en chat, en la creencia de que son el reflejo más fiel de las relaciones informales entre los participantes en la comunicación y de que es el tipo de texto más próximo a la comunicación hablada. Así nos lo ha expresado una de las jóvenes que ha colaborado en la investigación

pertsona berarekin komunikatzeko, desberdin idazten dut Whatsapp-etik edo email bidez... Tuentin, batik bat, lagunekin hitz egiten dudanez, nire euskalkia erabili ohi dut, arrotza egiten baitzait gertukoenei euskara batuan hitz egitea. Facebooken hizkuntza jasoagoa erabiltzen saiatzen naiz, sare sozial "serioagoa" iruditzen zait, eta hizkuntzaren erabilerak ere zuzenagoa izan beharko lukeela uste dut.... Hala ere, nire kasuan, joera dut txatean libreago idazteko: esaldi motzak, laburtutako hitzak, etab. erabili ohi ditut. Txatean, konfiantzazko lagunekin bederen, hitz egiten dudan bezala edo antzeratsu idatzi ohi dut. Mezuak idaztean, era formalagoan idazteko joera dut: esaldietako joskurak ongi egiten saiatzen naiz, puntuazioari erreparatzen diot eta paragrafoak banantzen ditut. Mezuak badu formalago egiten duen ezaugarri bat; agian, iraunkortasuna izan daiteke.

[Me comunico de manera diferente con la misma persona si escribo en Whatsapp o en un correo electrónico... Como uso Tuenti casi exclusivamente para relacionarme con mis amigos, utilizo mi dialecto, porque me resulta extraño hablar con mis cercanos en la variedad del vasco estándar, unificado. En Facebook intento usar un registro más elaborado, más formal, porque me parece que es una red más "seria" y creo que la lengua utilizada también debiera ser más correcta... Sin

\footnotetext{
1 Son chats exclusivamente textuales. En esta fase de la investigación prescindimos de los elementos audiovisuales. Según la opinión de algunos autores (Mayans, 2002) el hecho de ser, precisamente, solo texto aumenta la sensación de proximidad e inmediatez.
} 
embargo, yo por lo menos, escribo más libremente en el chat: frases cortas, palabras abreviadas... En el chat, con los amigos de confianza por lo menos, escribo de manera próxima a como hablo. Cuando escribo mensajes escribo de manera más formal: procuro unir bien las oraciones, me fijo en la puntuación, separo los párrafos... Los mensajes tienen una característica que los hace más formales; puede ser, quizá, su permanencia].

Esta reflexión pone en evidencia que los hablantes jóvenes eligen conscientemente el tipo de lengua y de escritura que usan; que distinguen cómo expresarse en función de para quién-para qué-en qué medio-qué-cómo. Y en todo ello, evidentemente, no es desdeñable el canal en que se desarrolla la comunicación. Aquí se puede observar, quizá, uno de los detonantes de uno de los tipos de cambio (¿revolución?) lingüístico (Crystal, 2001, p. 5).

The first task is therefore to investigate the linguistic properties of so-called 'electronic revolution', and to take a view on whether the way in which we use language on the Internet is becoming so different from our previous linguistic behaviour that it might genuinely be described as revolutionary.

Nuestro objetivo es precisamente mostrar algunas de las estrategias comunicativas, de los procedimientos, códigos lingüísticos, icónicos, simbólicos que eligen y utilizan los jóvenes en sus conversaciones virtuales.

De esta manera podemos ir construyendo una imagen (lo más certera posible) de la competencia de comunicación escrita de al menos una parte de la juventud vasca.

\section{Corpus analizado}

El corpus en una muestra constituida por 29 conversaciones reales mantenidas vía chat entre dos jóvenes guipuzcoanas entre el 1 de agosto de 2012 y el 14 de febrero² del año 2013.

El equipo de investigación está ampliando su objeto de estudio a conversaciones de más jóvenes vascos de ambos sexos, procedencias diversas, hablantes de otros dialectos distintos al analizado aquí, de otros ambientes sociales... con el fin de contrastar los resultados obtenidos en esta investigación.

\section{Lo oral, lo escrito e Internet}

Las relaciones entre los códigos escrito y hablado de las lenguas han generado una larga literatura. Su estudio se ha abordado desde diversos puntos de vista: son dos códigos independientes; el escrito es una especie de espejo del código primitivo, del hablado; ambos constituyen una especie de continuum; no tiene sentido hablar de tipología textual refiriéndose exclusivamente al soporte escrito, también hay que proponer una tipología para los textos orales... No se le puede negar vigencia, actualidad (y controversias) a la relación entre los dos códigos de expresión lingüística fundamentales: el oral y el escrito ${ }^{3}$.

En este sentido, nos atrevemos a apuntar los atisbos de una tendencia (no exenta de polémicas ${ }^{4}$ ) que se observa actualmente en algunos lugares vascófonos: grupos de hablantes (principalmente jóvenes) publican determinados tipos de textos escritos utilizando conscientemente un tipo de escritura que roza la transcripción fonética. Hay un alejamiento consciente de la normativa adquirida en la enseñanza -lo que veremos también en la escritura de los chats- que parece responder a la búsqueda de sintonía con hablantes también jóvenes (funcionaría como un elemento cohesionador, y un símbolo de libertad, como veremos más adelante). En este caso, no obstante, estos textos no se generan en una situación comunicativa privada y, al ser públicos, la relación entre el emisor y los receptores tampoco es necesariamente de proximidad o camaradería. Pero, en cualquier caso, el uso anormativo o fonético de la lengua escrita es el que prima, precisamente, en la escritura de los chats de las redes sociales de Internet.

Al lenguaje utilizado en Internet (lenguaje electrónico ${ }^{5}$, Borreguero, 2002; written speach, Crystal) se le atribuyen, entre otras, las características de que se escribe como se habla (se escribla6), que reúne las características de las lenguas oral y escrita, que es un

\footnotetext{
2 Queremos agradecer públicamente la colaboración voluntaria de las jóvenes.

3 Reflejo de ello es, entre otros, el reciente artículo "Dabrakotea enbargoyokua bezala" del crítico Beñat Sarasola en la revista Argia (2013.06.09, n² 2372), donde aboga por la independencia de ambos códigos, en la creación literaria al menos.

4 Es ejemplo de ello la discusión que generó la entrada "Idazteko moduez" [Sobre las maneras de escribir] del blog que gestinan traductores, escritores, profesores, investigadores... vascos 31eskutik http://31eskutik.com/2012/12/10/idazteko-moduez/\#comments

5 Se refiere sobre todo al de los mensajes electrónicos.

6 Nos hemos atrevido a valernos de este neologismo al verlo expresado también en un comentario de este blog:

${ }^{6}$ http://crecidasyafluentes.blogspot.com.es/2013/02/por-la-boca-muere-o-vive-el-pez.html. tomae dijo...ं has probado escriblar? hay quien lo dice palabrir...aunque un sabio cazador de ballenas me indicó que utilizara para comunicarme un verbo de la
} 
código mixto, intermedio entre ambos tipos de manifestación lingüística. Hay quien defiende que existe toda una tipología textual, que hay un continuum entre ambos extremos desde lo más oral a lo más escrito. Borreguero (2002, p. 315) recoge esa visión del continuum de Milena Collot y Nancy Belmore en 1996, quienes se basan, a su vez, en el modelo multi-feature analysis de Douglas Biber (1986, 1992)...

Por nuestra parte, hemos afirmado que no todas los textos que se publican en Internet poseen características similares, que los hablantes no nos comportamos de la misma manera, no utilizamos los mismos recursos lingüísticos ni escribimos de igual forma en todas nuestras comunicaciones, tampoco en Internet: no escribimos de la misma manera en nuestro blog personal y en la web de la empresa. Cuando nos comunicamos a través de mensajes electrónicos, y aunque algunos mensajes no se perciban muy lejanos a la comunicación oral, decimos que "escribimos" mensajes, no que "hablamos" mensajes, pero cuando nos comunicamos en un chat "hablamos" (¿escriblamos?) (Crystal, 2001, p. 29).

En cierto modo, pues, y, como observa Cassany (2012, p. 226), aunque los chats se usan para otros menesteres (académico, profesional...), lo cierto es que la lengua y la escritura de los chats es probablemente el tipo de texto que más se aleja de la escritura académica, reglada, formal..; la que se considera más próxima a lo oral, a las variedades habladas de la lengua. Por ello, al género chat se le ha considerado género híbrido, confuso (género confuso, Geertz, 1993, p. 8 (apud Mayans, 2002a, p. 40)), sobre todo, entre lo oral y lo escrito. Mayans titula el II. capítulo de su obra de 2002 "Género confuso: género chat" (2002a). Confuso, mezclado, pero no secundario (Mayans, 2002b. p. 1). Shank (1993) lo considera una variedad comunicativa multíloga, porque comparte las variedades oral y escrita de la lengua. Borreguero (2002, p. 314) define las conversaciones de chat como "simulaciones escritas de conversaciones orales"; Yus (2001a, 2001b), Gómez Torrego (2001), López Quero (2003)... los consideran "textos escritos oralizados a medio camino entre el habla y la escritura".

Más allá, Mayans (Mayans, 2002a, pp. 41, 95) considera que el chat es un género independiente, autónomo; posee características suficientes que sustentan su identidad:

Consideramos que las características externas e internas del género chat nos empujan a considerarlo un género en sí mismo ${ }^{7}$, que podemos analizar a la luz de los registros oral y escrito ${ }^{8}$, pero que sólo podremos comprender si lo utilizamos durante un tiempo determinado.... Su genuinidad específica se va descubriendo a medida que dejamos de pensarlo como sustituto de algo y lo vemos como un medio con un estilo y unas peculiaridades propias y singulares. Los contenidos de los chats y el medio -tecnológico- mismo que las hacen posibles dan lugar, por medio de una fusión creativa, impredecible, a un género - comunicacional, narrativo- distinto.... Es un género que ha dejado de estar a medio camino entre lo oral y lo escrito para situarse en otro lugar indeterminado y propio. El hecho de que sea un género en sí mismo nos sirve para entender por qué razón opinamos que los chats no sustituyen la comunicación oral, ni la escrita. Los mundos virtuales no le pisan el terreno a la realidad porque no ocupan el mismo lugar.

\section{Análisis de los chats}

Los chats se han convertido en objeto de atracción de diversas disciplinas (Antropología, Sociología, Filología, Lingüística, Pragmática, Teoría de la Comunicación....). También existe bibliografía abundante sobre la lengua y escritura de los chats, tanto trabajos de carácter más teórico como otros más descriptivos. De hecho, en los últimos años se han analizado y se continúan analizando chats escritos en diversas lenguas.

También se están analizando recientemente las conversaciones inmediatas virtuales que los jóvenes vascos establecen entre sí. Se han abordado sobre todo desde el punto de vista de la Sociolingüística (XV Jornadas de la sección tutelar de Euskaltzaindia de 2010, Barberena (2010), Basurto (2010), Cluster de Sociolingüística (2011, 2012), blogs de Amonarriz ("Algara edo ez gara") y Arantzabal ("Faroa")... $)^{9}$. La base común a todos ellos versa en la elección de lengua (vasco o castellano) de los jóvenes y adolescentes vascos.

Nuestro objetivo es describir algunos aspectos de la lengua y escritura de los chats en vasco, al modo que otros autores han analizado los de otras lenguas: Torres (2001, 2003), Blanco Rodríguez (2002), Borreguero (2002), Mayans (2000, 2002a, 2002b), López Quero (2003), Noguera (2006) ... y, por supuesto, Crystal $(2001,2004,2008,2011)$.

Dicho de otro modo, queremos detectar qué estrategias lingüísticas y comunicativas utilizan los usuarios de los chats vascos, teniendo en cuenta de alguna manera las de los usuarios de otras lenguas. En esta primera aproximación abordaremos los aspectos más evidentes de las señales escritas (tipo)gráficos (uso de las letras, de símbolos, puntuación...) y dejaremos para otra fase de la investigación otros ámbitos de las conversaciones virtuales (aspectos léxicos, morfosintácticos, organización del discurso...).

primera conjugación. Me lo dijo que utilizara el "escriblar" porque cuando escriblas, como su propio nombre indica todo queda con la contundencia de lo importante, ya sabes : La Palabra. (Negrita nuestra). [última consulta 13/12/2013].

7 En el original en cursiva.

8 No vemos adecuado mantener la dicotomía "registro oral" / "registro escrito". Parece implicar que el canal es el que condiciona el registro, Cosa que, ciertamente, no es así.

${ }^{9}$ Ahora tratamos fundamentalmente de los chats escritos en vasco. Dejamos a un lado otros tipos de

9 comunicaciones en vasco que se producen también a través de Internet y que se están estudiando actualmente: por ejemplo, mensajes breves de teléfono (Amonarriz, Urmeneta y Olariaga, 2003), de algunas redes sociales (Díaz Bizkarguenaga, 2011...) comunicaciones de los medios de comunicación y las redes sociales (Mallabiabarrena y Meso, 2012...), etc. 


\section{Written speech, charlas escritas (o escribladas)}

Partamos de la afirmación aceptada comúnmente: el chat es la conversación hablada, la charla oral escrita simultánea, o, mejor dicho, casi simultánea (Cassany, 2012, p. 73). Esa conversación se desarrolla en determinadas situaciones comunicativas y requiere de unas maneras de actuar adecuadas. Entre otras, hay que escribir con premura, rápidamente. Los mensajes han de ser breves. Deben producirse por medio de algún aparato o dispositivo electrónico que pueda acceder a Internet. Los interlocutores no tienen por qué estar presentes, pero deben estar conectados a Internet al mismo tiempo.

Para que la conversación se pueda desarrollar es completamente imprescindible que los participantes tengan un acuerdo tácito de colaboración, que tengan el propósito de contribuir a que la comunicación vaya desarrollándose; que se apoyen mutuamente. La conversación se va conformando, precisamente en el transcurso del ir y venir de las señales.

Los interlocutores, además, deben tener ciertas aptitudes y conocimientos: el uso del teclado; los sistemas de letras y números y otros códigos de signos, símbolos, figuras, emoticonos...; deben ser capaces de codificar y descodificar, de dominar el ciberalfabeto (Yus, 2001a, p. 112)..., deben ser competentes también en el manejo de la escritura ideofonemática (Cassany, 2012, p.

75; Torres, 2003, p. 80); escritura que no se aprende en el proceso educativo reglado.

En un intent de trobar un terme per a aquesta modalitat del català proposo anomenar-la escriptura ideofonemàtica. La justificació del terme es troba en el fet que aquesta escriptura, d'una banda, emula la transcripció fonètica amb els caràcters del teclat ex. «kern kedat» per «que hem quedat» i, de l'altra, juga amb els caràcters numèrics i matemàtics del teclat atribuintlos equivalències lingüístiques.

Es evidente, pues, que la actividad interactiva generada en este tipo de comunicación tiene unas características peculiares. Además, en general, el objetivo de la comunicación también es singular: comunicarse por comunicar, por el puro placer de disfrutar de la conversación (Noguera, 2006, p. 63), del contacto con el otro. El objetivo está también íntimamente asociado al ocio, a lo lúdico.

El objetivo del chat es recuperar el placer de hablar, esto se logra a través del intercambio continuo de interacciones verbales y "orales" (no en vano ¿quién diría que tal persona me ha "escrito" tal cosa en el chat, en lugar de decir que me la ha "dicho"?) se trata de estar con alguien sin estar a su lado, de estar a su lado sin tenerlo cerca y por ende, de no estar solo.

La mayoría de las veces, las conversaciones son espontáneas e informales. Se pretende reforzar los vínculos personales entre los interlocutores (Blanco Rodríguez, 2002, pp. 41-42). Más aún, como hemos mencionado anteriormente, el tipo de escritura ideofonemática puede constituir para los jóvenes un símbolo de juventud, de identidad, de libertad (Mayans 2002a, 2002b; Noguera, 2006, p. 73).

Los chats privados y ociosos entre adolescentes suelen ser el ejemplo más claro: para ellos este tipo de escritura es una marca de identidad y evitarla sería inapropiado e incluso una manera de (auto)excluirse; ...los jóvenes usan la escritura ideofonemática para construir una identidad personal en la red, para distinguir su escritura del resto, a modo de ideolecto.... Por otra parte, al margen de que los jóvenes sean más o menos conscientes de este hecho, la escritura ideofonemática asume el propósito social de discutir el estándar 0 , en definitiva, de rebelarse contra la norma establecida. (Cassany, 2012, p. 76)

La situación comunicativa condiciona las características de este tipo de conversación y es importante que los investigadores también lo tengamos en cuenta. No parece tener mucho sentido pretender abordar la investigación de los chats según parámetros de otros tipos de procesos comunicativos escritos, pues se pueden obtener conclusiones desafortunadas. Entre otras, en primer lugar, que los chats están plagados de incorrecciones, que los elaboradores de los chats ("los jóvenes") desconocen las más mínimas reglas de ortografía, puntuación, morfosintaxis..., que en los intercambios de mensajes prima la incoherencia, que se está destrozando la lengua porque se escribe cualquier tipo de texto como si fueran chats... Seguramente no son los criterios (¿prejuicios?) más adecuados para profundizar en las características comunicativas de este tipo de discurso ${ }^{10}$.

Nuestra investigación prescindirá de otros aspectos desde los que se pueden (y deben) abordar estas formas de comunicar y se basará fundamentalmente en algunos de los elementos del soporte lingüístico de las intervenciones del chat. Para ello contaremos como referencia, entre otros, con el trabajo de Torres "La llengua catalana en la comunicació a Internet: questió de codis" (2003). Torres (2003, pp. 80-81) atribuye a la escritura ideofonemática del catalán dos características fundamentales: utilizar un código simplificado y ser una lengua creativa, innovadora. Cassany posteriormente (2012, p. 77) toma como base esas dos características de Torres y las adecua al español.

10 Traemos estas palabras a modo de ejemplo: "Los chats, como acabamos de ver, están dotados de estilo informal (incorrección ortográfica y expresión defectuosa), ortografía fonética (distorsiones textuales, como (29) imeil, d'estas); rasgos sociolectales; representación prosódica (repetición de letras, mayúsculas, signos de puntuación, tipografía); manifestación interlingüística (adaptaciones de préstamos); equivalencia homofónica mediante sustituciones léxicas y grafémicas (30) qu>k, $\|>y$, ch>tx; abreviaciones, acrónimos y siglas (31) tb., xa., e-mail, e- banco, www, EMS como formas peculiares de chat; frases truncadas y elipsis. Así tanto las estrategias compensatorias de la ausencia de información no verbal como las estrategias textuales conforman el nuevo texto electrónico representado en el chat". (Cervera, 2001). 
De ambos trabajos se desprenden las siguientes características que intentaremos contrastar con nuestra muestra del vasco: conforman el código simplificado no usar vocales, reducir los grupos consonánticos, no utilizar ni tildes (en vasco no las hay) ni signos de puntuación de cometido sintáctico, no usar letras mayúsculas ni al principio de las oraciones ni con los nombres propios, utilizar abreviaturas, utilizar cifras y símbolos...

Al uso creativo, innovador de la lengua corresponden, por su parte, crear palabras, utilizar los nombres de los números según su expresión oral ("7mana" setmana), los símbolos matemáticos con otros valores ("x" para significar la preposición per, "+" para el adverbio més...), signos con valor simbólico (@ para incluir los morfemas de ambos géneros ${ }^{11} \ldots$...); utilizar recursos de los cómics: letras mayúsculas para significar gritos; signos de admiración, interrogación, puntos suspensivos... para expresar actitudes, disposiciones delos hablantes; usar la letra z para indicar somnolencia, aburrimiento...; repetición de signos para denotar énfasis, emoticonos para mostrar estados anímicos... Todo ello junto con signos procedentes de los mensajes de los teléfonos móviles como las abreviaturas, las mezclas de lenguas, los insultos, formas toscas, vulgares...

Mayans (2002a) también hace suyas las opiniones de otros investigadores y añade que, en su opinión, los autores de chats cometen "incorrecciones" conscientemente por tres motivos principales: la velocidad de la escritura, la falta de componentes extra- y paralingüísticos y la necesidad de intentar buscar la proximidad, la camaradería, el humor... Respecto a este último aspecto afirma que la búsqueda de lo lúdico está unida a poner en cuestión las normas ortográficas y gramaticales, además de intentar conseguir originalidad, creatividad, viveza. Unidos a esa especie de "incorrecciones", atribuye también otras características a la escritura de los chats: uso de las mayúsculas para denotar gritos y uso (que le resulta) sorprendente de la letra "k"12.

Como hemos mencionado anteriormente, en nuestro análisis tendremos en cuenta la visión de varios autores, pero también queremos subrayar que a menudo el mismo hecho puede deberse a más de una razón. Por ejemplo, quien ha escrito "bñ" para expresar baina [pero] ha abreviado la palabra para poder escribirla más rápidamente, pero esa escritura también refleja la pronunciación del escritor, su variedad lingüística geográfica: pronuncia la consonante nasal palatalizada [baña], como lo hacen los hablantes de algunos dialectos del vasco (a diferencia de otros que no lo hacen [baina]).

\section{Características de los chats analizados}

Adelantemos que en nuestro análisis hemos observado numerosos ejemplos de las características señaladas por los investigadores de otras lenguas, tanto de las atribuidas al código simplificado utilizado en los chats como de las relacionadas con la innovación y la creatividad lingüística. Daremos cuenta de algunos de ellos, limitándonos fundamentalmente a los aspectos señalados anteriormente.

\section{Errores}

Este tipo de escritura refleja a menudo errores involuntarios. El emisor comete errores al pulsar alguna tecla rápidamente, como, por ejemplo, el "7" del final y el "4" escrito dentro de la palabra:

\section{zorionaaaaaaaaaaaaaaaaaaaaak7; Ntxe z4arru erretzen}

En los ejemplos que recogemos a continuación se puede adivinar más claramente el motivo del error. Sobra la "v", han confundido la "a" y la "s", han equivocado las nasales: "mb" en lugar de "nb". La confusión puede deberse a que en el teclado están contiguas las letras "b" y "v", "a" y "s", "m" y "n", respectivamente, si bien es cierto que en el último caso también puede tratarse de la influencia de la ortografía del españoli3.

ez,beste bati, oiandala urtebvete eo hiltzanai; Jsjaja; Y:Ordubatak ambun; Si egye esan nayo lana iti tamboradan santototan bño

Pero esos errores no impiden la comunicación. Además, hay una predisposición de los interlocutores para restaurar y reparar los errores del otro. Probablemente ni siquiera son tenidos en cuenta como tales.

Sin embargo, en ocasiones, el receptor requiere de alguna aclaración para poder asegurar la interpretación correcta de la señal recibida. En nuestro caso, la autora del error corrige su texto y así se puede continuar el proceso comunicativo.

El siguiente es un buen ejemplo que muestra la cooperación entre los participantes, y el humor que salpica frecuentemente este tipo de conversaciones de chat. La participante $\mathrm{X}$ ha escrito "txugixk". La receptora $\mathrm{Y}$ no está segura de cómo hay que interpretarlo y responde

11 En la lista de Crystal $(2008$, pp. 189, 297) utilizan el mismo signo para significar las preposiciones at en inglés y à en francés (“@2ml”(á demain). No da cuenta de los usos en español y catalán. En vasco no hay morfemas de género en el Sintagma Nominal.

12 Como símbolo la une a actitudes revolucionarias ("Mili-kk", "okupa"...). Sin embargo, en vasco no tiene

12 connotaciones especiales, es una (más) de las letras del alfabeto.

13 Dicho sea de paso, en este caso la del español más fonética que fonológica. 
proponiendo otra palabra que se supone comparten ambas ("txumgo"). No obstante, Y ha cometido un error y ha utilizado "m" en lugar de "n" ("txungo"), lo que aprovecha X para corregir a quien había corregido, Y.

$X$ : Bier medikuna nue, bzpare $z$ lepue txugixk dakt

$\mathrm{X}:$ Ba igual deitzeizt 5 tak aldea:)

Y:Txugixk?

\section{Txumgo \\ $\mathrm{X}$ :Txungo \\ Ajaja \\ Y:Jajaja}

Letras áfonas ("h")

Una de las estrategias para ganar rapidez en la escritura puede ser no escribir letras áfonas (la "h" en la mayoría de los dialectos del vasco lo es), sobre todo si dicha letra no tiene valor fonemático (por ej. hona [aquí] y ona [bueno]...). Sin embargo, las autoras de la muestra utilizan a menudo la letra "h", aunque no siempre de la misma manera: escriben la misma palabra a veces con "h" y otras sin ella.

Las interlocutoras respetan en general la ortografía normalizada; usan la grafía con "h" en la mayoría de las palabras que en la escritura normativa la tienen: hartzea [tomar], hamaiketan [a las 11], hor [ahí], hobeto [mejor], ahzpe [hermana], hllabete [mes], herriye [pueblo]... Hay pocos ejemplos de palabras que no se ajustan a las normas ortográficas en el uso de la "h".

Biher / bier; Hurrengo / hurrengo $(X)$, ureng $(Y)$

Y: Ala ainaz

X: auskalo igual oixe infeziyu zaken

Y: Loik partdu dke ustet 4 tan $t$ area guz ane $t$ ni
[Hala ari naiz]

[horixe]

[hara]

Estos ejemplos desmienten la opinión (más o menos generalizada) de que la escritura de los chats es una "transcripción" del habla, que es un modo de escribir totalmente ajeno a la normativa ortográfica. El uso de la "h" de las autoras de los chats analizados aquí es el uso normativo adquirido en la escuela. Ellas no pronuncian la "h".

La ortografía regulada, académica, tiene su reflejo en la escritura del chat; se puede decir que es uno de sus componentes.

Falta de vocales, falta de consonantes

En la muestra faltan frecuentemente las vocales, pero las palabras son inteligibles en su contexto. Observamos que actúan de manera similar en las palabras de los dos códigos lingüísticos que combinan, el vasco y el español:

btekin, btek [batekin, batek]; bstla [bestela]; dnstim? [Donostin]; nbzu [nahi baduzu], pentstzt [pentsatzet $=$ pentsatzen det]

ns [nos], dspedir [despedir], Lgaste [Ligaste], Qdams [Quedamos]

También faltan consonantes (sobre todo intervocálicas). Pero parece que responde a razones distintas a las de la falta de vocales.

En todos los casos la premura con la que se escriben los textos puede ser la causa de las ausencias de letras, pero, a diferencia de la falta de vocales, la falta de consonantes responde asimismo al intento de transcribir lo oral al código escrito y, por ello, también es un medio de expresar cercanía, proximidad, informalidad.

Afaltzea kanpoa bai?

ske tarragonako ber deu [degu] ta oindik eztakeu [ez daukagu]

X: eei ba ni juxtu $11 \tan$ nao anbun gerauta [afaltzera kanpora]

[nago] [geratuta]

Abreviaturas 
El uso de las abreviaturas es bastante regular. Las más utilizadas son estas seis: "t": Expresa la conjunción copulativa eta [y]. T esantziten; gñea jndik esantzin ostiralin bajue jotzezula t jteko arrasatea t gero bere etxin iteko lo

"zm", "zmz": zer moduz [qué tal]. Joe tio...ta iraid zm eo?; Zmuz atzoo? "bñ(o)": Baina [pero], baino ["partícula comparativa"] bño bestela etorri nbzu; Topau nun beñ t htzeñgenun bñ yasta gexo enun ikusi

"nd": ondo [bien]. Bestela zm? Zapatn nd; Leiree! Pos ementxe nd antzea

"bt": bat [uno]. Kaf bt hartzeko; 3terditan peli bt ikusteko geauta nao,t 6retan dakt geo lan

"ske": es que. T nun erosi zun eo? Z ber dt t eztakit nun lortu, ske atzo abxau ziben lerdo mari oyek; Ni seguruna berdanduo ske zinea nue

Estas formas abreviadas hacen preguntarse sobre otro aspecto de la relación entre lo oral y lo escrito. Si se escribe (aun de manera interpretable) sin vocales, por medio de abreviaturas... impronunciables, ¿se puede afirmar sin resquicios que la característica del género chat es que es el género oral escrito? Parece más apropiado afirmar que la escritura de este género corresponde más a que lo escrito se puede interpretar, inferir (pero no literalmente leer o descodificar) que a "la escritura de lo que se dice"

Por otra parte, topamos nuevamente con la necesidad de colaboración, de solidaridad de los interlocutores. El descodificador-intérprete debe gestionar la señal codificada que ha recibido para su comprensión, y el codificador también debe esforzarse en convertir en señal clara, o por lo menos, interpretable, ese mensaje del que quiere que el receptor participe. Y lo debe hacer sin demasiada dilación.

Y ello nos lleva a preguntarnos también por la relación entre la rapidez, la economía y la facilidad para escribir. Se destaca, y es innegable, la característica de la rapidez en la escritura en los chats y de la economía de la misma (tener que efectuar el menor número de pulsaciones). No obstante, este mismo hecho exige un esfuerzo mayor al escritor (y al receptor) alfabetizados en otro sistema de escritura, ya que necesitan elaborar rápidamente un sistema compartido, en lugar de usar el que ya dominan. Pero el éxito de este sistema de comunicación escrita pone en evidencia que a los hablantes les resulta satisfactorio dicho esfuerzo.

Evidentemente, en este "juego" la creatividad también tiene su importancia. El sistema de escritura aprendido en la escuela no es válido en su totalidad en este tipo de comunicación, en este género (no se enseña, no se aprende en la escuela a escribir para los chats), pero, al mismo tiempo, la competencia lingüística y la competencia comunicativa que trabajan los interlocutores (también, ¿sobre todo?) en la escuela son fundamentales para poder producir y entender el código "abreviado".

Falta de silabas, unión de palabras, fonetismos, palatalización...

Frecuentemente las autoras tienden a simplificar los grupos vocálicos. Faltan sílabas, morfemas. Puede explicarse la ausencia por las mismas razones aducidas anteriormente: rapidez e intento de aproximación a lo oral. Reflejan el habla de su entorno lingüístico.

Escriben a menudo sin separación el verbo principal y el auxiliar, tal y como como lo pronuncian: esantziten [esaten zidaten], ezautzezu [ezagutzen duzu], operatzebe [operatzen dabe], emateit [ematen dit], ustetgaldeukoyoot [uste det galdetuko diot], eongozea [egongo gara]... También abrevian otros componentes del sintagma verbal (behar [necesitar] muy frecuentemente es "be"): inbet [egin behar det], inbezun [egin behar zuen], junbet [joan behar det]... Las palabras del español que utilizan las abrevian de la misma manera: "saes" [sabes]

t atzo etxeakun otzñ imtziten [etxerakoan]; gauz bat batemat [baten bat] ezautzezu [ezagutzen duzu] kanpiñe dakenaa..[daukana] ske tarragonako ber [behar]deu ta oindik [oraindik] eztakeu [ez daukagu]

Asiq ya tu saes mamita [sabes]

Asimismo, reflejan los cambios de vocales... propios de su variedad dialectal:

nue (noa); nun (non); gaue; sue; goizin; esperientziye; atatze zeanin; aurrekun;

zapatun; ginasiyun

4retan ayatze naiz

La palatalización consciente es síntoma del habla expresiva, afectiva, lúdica... Las jóvenes recurren frecuentemente a reflejarla en la escritura: 
Zergaitxik, gaxki, axkoitin, polittek, maiteño; pitxilore; Patxuu [musu adierazteko]; patxotee

Recursos para expresar énfasis, tono, modulación, volumen...

Los recursos más frecuentes son la repetición de las vocales, el uso de letras mayúsculas, el de varios signos de admiración, las onomatopeyas, repetir las intervenciones... Son todos ellos elementos que utiliza el emisor del mensaje para tratar de expresar gráficamente los componentes para- y extralingüísticos —la comunicación no verbal y no lingüística - de los hablantes que en las conversaciones in praesentia se exteriorizan a través de la voz, los gestos, los movimientos... y que son determinantes para que e receptor, además de descodificar el enunciado lingüístico, infiera, interprete y elabore su representación interna (Escandell, 2005). Es un campo propicio para la innovación lingüística.

Interesa señalar que las interlocutoras combinan en sus intervenciones con toda naturalidad expresiones de varios códigos lingüísticos ${ }^{14}$ : vasco, español (e inglés) fundamentalmente, sobre todo en el ámbito de las exclamaciones, onomatopeyas...

Exclamaciones, onomatopeyas. Son muy abundantes y variadas. Destacamos que, a pesar de comunicarse entre mujeres, utilizan la forma masculina "tio" para referirse a ellas mismas.

Uf; Jajajaja; Uajajaja; bua gaur berrriz ke buena; Jajaja atzo d lasaii; atzooo ez..jajajaj; Jajaja ke tia; bua urrengo astin amama operatzebe ya..; 0 ez? ezez osakidetzan; Pff; Patxote pitxinitaMuaa

ke buena; baii; einga; Jajajaja; eei; Uuu; ui; Psss; Yeah; bua; ya; bo; okei, Okey; okei perfekt; Pos; pff; Toope!; Olee; Yasta; pos xastaa; aa tzaatzii:);baai zeeaaa..ostia ba ezer enekiyeen..; Joe tio...; Jo tope!; aupa tio; kauen zozttzzzz; Tranki; sinms...

Vocales repetidas. Son muy frecuentes.

zorionaaaaaaaaaaaaaaaaaaaaak7; leireeeeeee; eskerrikaskooo; atzooo; zemuuz?; muxuuu; pasauu;

Letras mayúsculas. Las usan en pocas ocasiones. No hay que olvidar que su uso frecuente se puede interpretar como algo ofensivo. Utilizan con más frecuencia las letras minúsculas, incluso en los casos en los que la norma ortográfica indica lo contrario: nombres propios etc.

Repetición de signos de interrogación y admiración. También recurren a ello, junto con la repetición de las vocales.

Los puntos suspensivos se utilizan frecuentemente, aunque no siempre tres: a veces utilizan dos y otras veces más de tres. No parece haber un control excesivo en el número de puntos a escribir.

Emoticonos. En la literatura se destaca el uso y valor de estos elementos gráficos (Torres 1999,

2001); tampoco faltan largas listas de ellos. Como hemos señalado anteriormente, el emisor usa estos elementos para ayudar al receptor en la descodificación y, sobre todo, en la inferencia de la señal que recibe. Nuestras hablantes han utilizado muy pocos emoticones, y pocas veces. Entre los dos hablantes hay una gran diferencia en su uso: la hablante $\mathrm{X}$ es mucho más prolija en su uso que la hablante Y.

Hemos detectado solamente estos emoticonos. La función de todos ellos es dulcificar la imagen; expresan relaciones de cordialidad, de complicidad. No hay ningún emoticono que denote enfado, disgusto...

:) () sonrisa; :D risa; ;) Guiño de ojos; X:) $)^{15}$

Casi siempre los escriben pegados a la última palabra. Cumplen la función de cerrar el enunciado, al modo del punto ortográfico:

X: alee poxpolintxu banue lota, biher bestela enaizela jaikikoo, ta zurire komeni;)

X: Oain biblin nao emendik 10min ea deitzeizt:D

14 La mezcla de los códigos lingüísticos merece por sí sola más atención que la que aquí ahora le podemos ofrecer.

15 Más adelante nos referiremos a nuestra dificultad para acotar este símbolo. 
X: Ba igual deitzeizt 5tak aldea:)

A veces los añaden tras los signos de interrogación o admiración. Su función puede ser enfatizar el valor de las interjecciones, de las expresiones vocativo-conativas.

\author{
X: 9tan mireiakin geau naiz iraurgin, 10gutxi kabinan???:) \\ X: oooiiixx!!:
}

$\mathrm{X}$ : Jondi eztaola usteet!beinga tu; )

Zu zemuz? Bier kaftxo bai ala bai tio:)

Pueden sustituir a una palabra, a un cuantificador. En este caso no son modalizadores del enunciado, como en los casos anteriores, sino componentes del propio enunciado. Es otro ejemplo de innovación lingüística.

Jo eskerrik:D

Signos de puntuación

Es evidente que en los chats no se utilizan los signos de puntuación del mismo modo que en otros géneros textuales. En primer lugar, hay que tener en cuenta que la disposición y distribución gráfica, el scroll, la anchura de la banda...; es decir, los medios tecnológicos condicionan el propio proceso de la escritura.

En otros géneros y tipos textuales (en este mismo texto que estamos escribiendo) la distribución en párrafos, en enunciados textuales (marcados por los puntos internos del párrafo), en secuencias textuales (delimitadas por los puntos y comas) es crucial. En una palabra, la disposición gráfica del texto en todos sus aspectos es un espejo de la disposición conceptual que tiene del texto su elaborador, así como del tipo de competencia de pensamiento que se trata de desarrollar en él: el pensamiento discursivo, encadenado... parece requerir un tipo de texto que permita secuencias y pasajes de cierta longitud. No parece que el chat sea la mejor vía para hacerlo.

En los chats se utilizan menos signos de puntuación y con menos frecuencia que en otros tipos de textos. Al igual que los usuarios de otras lenguas, los jóvenes vascos se valen de comas, puntos y, sobre todo, de signos de admiración e interrogación. Estos últimos para reflejar el estado de emoción, las impresiones..., la información paralingüística del hablante. No utilizan ni el punto y coma, ni paréntesis, ni dos puntos (excepto en los emoticonos $\left.{ }^{16}\right)$... ni otros signos de puntuación. Por otra parte, aunque no cuidan el uso de los espacios vacíos alrededor de los signos de puntuación sí dejan a menudo (no siempre) un espacio vacío a continuación del signo.

Punto. Apenas lo usan. Todo indica que el cambio de intervención sustituye al punto final. Los mensajes han de ser breves necesariamente, porque así lo exigen la situación comunicativa del intercambio y el medio que se utiliza. Por lo tanto, se escribe de manera fragmentada. Una idea que constituiría un párrafo, al no estar bien aceptado entre los usuarios de chats escribir textos largos, se descompone en enunciados breves (en mensajes) que se envían muy seguidos y dan al receptor la impresión de unidad.

$\mathrm{X}$ :bai gaur bai..jai alaira jun gea gurasukin afaltzea anaye ta ni ze ezkondu ziela

22urte iteituzte biher

ta ez naonez ba gaur jun gea

biyer atzaldin nue ubidea..ta emendik aurrea gehienetan olaxe asike ondo

En los casos en los que se han usado dos puntos, uno a continuación del otro, dudamos si la autora del chat quería usar un punto ortográfico o los tres puntos suspensivos. Creemos que, en algunos casos por lo menos, quería escribir uno, pero descuidadamente ha escrito dos. También hemos detectado dos comas seguidas en algún caso.

baitaa!! kriston gustoa ibili nitzeen iye gau osue zakelan pasau genun, azeitunak jatek..

X: bai neskaa...ikusiye zueen,

16 Noguera (2006, p. 64) recoge también el uso de los paréntesis para intercalar en una intervención algún enunciado parentético. 
Coma. La usan menos que en otros tipos de textos y cuando lo hacen es para marcar pausas dentro de la intervención del mismo hablante. Frecuentemente es un recurso que suple a conjunciones coordinantes o subordinantes (las unidades que distinguen gráficamente los puntos y/o los puntos y comas). Dicho de otra manera, es un soporte gráfico de la yuxtaposición.

Ale maiteño banue, bier te xamo! Ostirelearte,muxuu; alee poxpolintxu banue lota, biher bestela enaizela jaikikoo, ta zurire komeni;) Dígitos y letras juntos. Se cita esta característica como síntoma de la premura en la escritura. En vasco, fuera de la escritura digital, es habitual combinar dígitos y letras. Dado que se expresan por medio de sufijos las relaciones sintagmáticas, en el caso de la expresión de las horas, por ejemplo, en textos de todo tipo, incluidos los más formales, es habitual unir ambos alfabetos. Las autoras de los chats lo han hecho de la misma manera.

4trditan geauta nao; 5terdtn etxea; biher nue 4terditan ya egurrea

No obstante, sorprendentemente, en algún caso expresan por medio de letras ("hamaiketan" [a las once]) lo que podían haber escrito más rápidamente, por medio de números, justo como lo hace en otra intervención la misma hablante:

Hamaiketan azpeitik erten; eei ba ni juxtu 11 tan nao anbun gerauta

No hemos observado ejemplos de uso del nombre del número expresado y entendido como si fuera una palabra. Es decir, no hemos visto algo semejante al título del primer capitulo de Crystal (2008): "2b or not $2 \mathrm{~b} . .$. tht is th?".

Hemos constatado un caso en el que se trasluce que el sistema de escritura que utilizan no es algo definido y cerrado, sino que está en proceso de elaboración. No hemos sabido cómo interpretar un signo: el símbolo de la suma +, que ha usado dos veces la misma hablante.

Jaja+ikus dtt fotuek oso polittek; Knektata dao,t beake jokatzeula uste+

En el primer caso parece sustituir a la conjunción coordinante eta [y] y en el segundo parece haber usado el símbolo matemático en lugar del verbo auxiliar transitivo dut. ¿O es un descuido digital al final de la intervención?

Y nos ha ocurrido lo mismo con un signo (complejo) que no sabíamos cómo delimitar. ¿Cuál es el emoticono? ¿"nbX:)"?, ¿"bX:)"?, ¿"X:)"?

Animau nbX:)

Parece que quería escribir "nbz" nahi baduzu [si quieres], pero ha escrito, sin querer quizá, "nb" y junto a ello el emoticono de información paralingüística "X:)". Interpretamos que quería invitar a la otra persona a algo y le quería animar: "animatu, nahi baduzu (poza)" [anímate, si quieres (te lo digo contenta, me alegraría que aceptaras la invitación)].

Nos hemos sentido reflejadas completamente en estas palabras de Cassany (2012, p. 78):

Hay poca sistematicidad en la escritura ideofonemática, o sea, por qué la simplificación (elisiones, omisiones, emoticonos) carece de regularidades y varía en los escritos de un mismo autor y entre los de autores y lectores de un mismo grupo social; incluso en un mismo escrito no siempre hay regularidades en el uso de estas reducciones. A menudo es imposible determinar si son una lección premeditada del autor, un error ortotipográfico fruto de la ignorancia o un hecho azaroso.

\section{A modo de epílogo}

Los jóvenes vascos están desarrollando su código de comunicación escrita para establecer relaciones comunicativas en unos ámbitos de relación y comunicación nuevos, desconocidos para las generaciones anteriores.

No creemos que el tipo de escritura que utilizan en los chats de Internet se deba al desconocimiento de las reglas de ortografía, de puntuación, de gramática... de su lengua. Si bien es cierto que la celeridad, los lapsus digitales, e incluso el desconocimiento pueden estar en el origen de algunas formas de escritura no normativas, no creemos que sea la razón principal que les impela a hacerlo así; escriben de esa manera conscientemente, deliberadamente, condicionados por el medio, por todos los componentes del proceso comunicativo y con el fin de buscar una comunicación más expresiva, más cercana, más viva, más divertida... (Mayans, 2002a, p. 82).

Los usuarios de los chats, por la sola razón de usar el chat, no deterioran su conocimiento de la lengua (Mayans (2002a, 2002b), Crystal (2001, 2008), Noguera (2006), Cassany (2012)...). Al contrario; también se puede pensar que dedican más horas a escribir que lo que le dedicarían si no participaran en los chats de Internet. El hecho de tener que escribir, de tener que desarrollar la escritura ideofonemática, de tener que utilizar la lengua de manera creativa, pero de manera compartida, les obliga a tener que pensar en la lengua y a buscar 
soluciones para los problemas que les plantea la creación de un tipo de escritura (Crystal, 2008, p. 175).

Some people dislike texting. Some are bemused by it. Some love it. I am fascinated by it, for it is the latest manifestation of the human ability to be linguistically creative and to adapt language to sit the demands of diverse setting. In texting we are seeing, in a small way, language in evolution.

Este uso de la lengua no coincide con lo normativo, con lo académico, con la lengua estándar... y eso es motivo de preocupación para algunos hablantes; más, si cabe, si es el caso de una lengua que tiene dificultades para su pervivencia y desarrollo, como lo es el del vasco.

Esta investigación pone de manifiesto que los jóvenes vascos no son una excepción en sus actitudes innovadoras: están creando su código escrito en vasco para comunicarse en los chats entre ellos. El chat puede ser el espacio de comunicación en el que se pueda jugar y escriblar prescindiendo de las "normas".

Pensamos que es más enriquecedor pensar, como Cassany (2012, p. 55), que hemos ganado otro espacio para comunicarnos también en la lengua vasca.

La escritura hoy dispone de un repertorio verbal tan diverso como el habla (estándar / dialectal, completo / simplificado, formal / informal). Por ello, escribir hoy exige dominar una gama más variada de variedades y registros.

\section{Referencias Bibliográficas}

Amonarriz, Kike, Urmeneta, Asisko, Olariaga, Antton (2003): SMS: segapotoen mezu sekretuak. Buruntzaldeko udalak.

Blanco Rodríguez, Ma José (2002): "El chat: conversación escrita”. Estudios de Lingüística,16 (monográfico). Alicante.

Borreguero Zuloaga, Margarita (2002): "Entre oralidad y escritura: la lengua del correo electrónico y de los debates virtuales". Presentado en el IV Congreso de Lingüística General: Cádiz. 3-6 de abril de 2000, II, pp. 307-317.

Briz Gómez, Antonio, Serra, Enric (1997): "De lo oral y lo escrito y entre lo oral y lo escrito" In Briz Gómez, Antonio, Cuenca Ordinyana, Maria Josep, Serra Alegre, Enric (eds.): Sobre l'oral i l'escrit. Universitat de València, pp. 1-6.

Cassany, Daniel (2011): En-línia. Llegir i escriure a la xarxa. Barcelona: Graó. [(2012): En_línea. Leer y escribir en la red. Barcelona: Anagrama].

Cervera, Ángel (2001): "La irrupción del coloquialismo en Internet y las nuevas tecnologías". Presentado en el II Congreso Internacional de la Lengua Española. El Español en la Sociedad de la Información. Valladolid. [http://congresosdelalengua.es/valladolid/ponencias/nuevas_fronteras_del_espanol/4_lengua_y_escritura/cervera_a.htm 2001 útlima consulta el 13/12/2013].

Crystal, David (2001): Language and the Internet. Cambridge: Cambrigde University Press.

-- (2004): La revolución del lenguaje. Madril: Alianza Editorial. [(2007): Hizkuntzaren iraultza.

Donostia: Erein]

-- (2008): Txtng. The gr8 db8. Oxford: Oxford University Press.

-- (2011): Internet Linguistics: a student guide. Oxford: Routledge.

-- (?): "Hizkuntza, hizkuntzak $\quad$ eta Inttp://www.euskara.euskadi.net/r59bpeduki/es/contenidos/informacion/artik25_1_crystal_08_06/eu_crystal/adjuntos/David-Crystal.pdf, última consulta el 13/12/2013] Díaz Bizkarguenaga, Koldo (2011): "Euskal identitatearen garapena online sare sozialen bidez: gazteen praktika sozialak Facebooken". Gogoa, 11 (1), pp. 61-85.

Escandell Vidal, Ma Victoria (2005): La comunicación. Madrid: Gredos.

Euskaltzaindia (2010): "Gazteak, aisialdia eta euskara". Presentado en XV. JAGON Jardunaldiak.

Euskera 55 (2). [http://www.euskaltzaindia.net/dok/euskera/75378.pdf, última consulta el 13/12/2013]. 
Gómez Torrego, Leonardo (2001): "La gramática en Internet". Presentado en el II Congreso Internacional de la Lengua Española. El Español en la Sociedad de la Información. [http://congresosdelalengua.es/valladolid/ponencias/nuevas_fronteras_del_espanol/4_I engua_y_escritura/gomez_l.htm, última consulta el 13/12/2013].

López Quero, Salvador (2003): El lenguaje de los 'chats'. Aspectos gramaticales. Granada: Port- Royal Lingüística.

-- (2010): "Marcas gramaticales de oralidad en los chats y foros de debate: Incorporación de marcadores discursivos del español hablado". Oralia 13, pp. 173-195.

López Quero, Salvador; Calero Vaquera, Ma L.; Zamorano Aguilar, A. (2004): "Foros de debate vs. otros discursos electrónicos". Español Actual 82, pp. 53-75.

Mallabiabarrena, Itxaso, Meso Ayerdi, Koldo (2012): "Sare Sozialak euskal ziberkomunikabide esanguratsuenetan”. Euskonews 632. [http://www.euskonews.com/0632zbk/gaia63202es.html, última consulta el 13/12/2013]

Mayans i Planells, Joan (2000): "Género confuso: género chat". Revista TEXTOS de la CiberSociedad, 1. Temática Variada. [http://www.cibersociedad.net, última consulta el 13/12/2013]

-- (2002a): Género Chat. O cómo la etnografía puso un pie en el ciberespacio. Barcelona: Gedisa.

-- (2002b): "De la incorrección normativa en los chats". Revista de investigación Lingüística, 2, V, pp. 101-116. Observatorio para la CiberSociedad: [http://www.cibersociedad.net/archivo/ articulo.php?art=43\%20target, última consulta el 13/12/2013].

Noguera Vivo, José Manuel (2006): “La oralidad del chat en estudiantes universitarios". AlterTexto 7, 4. bol., pp. 59-76.

Perez Gaztelu, Elixabete; Zulaika, Esther (2012): Idatziz komunikatu. Gazteak eskolan idazten. Donostia: Deustuko Unibertsitatea.

Perez Gaztelu, Elixabete; Zulaika, Esther; Muñoa, Ion (2011): "Puntu bat, bi puntu, hiru puntu... Puntuazioa Gipuzkoako gazteen eskola testuetan". Ikastaria, 17, pp. 155-205.

Sarasola Santamaria, Beñat (2013): "Dabrakotea enbargoyokua bezala". Argia 2372, http://www.argia.com/argiaastekaria/2372/dabrakotea-enbargoyokua-bezala, última consulta el 13/12/2013].

Soziolionguistikako Klusterra (2011): "Nerabeak, interneteko sare sozialak eta euskara" [http://www.soziolinguistika.org/nerabeaksaresozialak, última consulta el 13/12/2013].

-- (2012): "Gazteak, sare sozialak eta hizkuntza kudeaketa. Kasu arrakastatsuak. Gakoak. Jarraibideak".

Andoainen, 2012ko abenduan [http://issuu.com/skluster/docs/txostena_behin_betikoa, última consulta el 13/12/2013].

Torres i Vilatarsana, Marta (1999): "Els xats: entre l'oralitat i l'escriptura". Els Marges 65, pp. 113-126. [http://www.raco.cat/index.php/Marges/article/viewFile/111280/156746, última consulta el13/12/2013].

-- (2001): "Funciones pragmáticas de los emoticones en la comunicación mediatizada por ordenador" [http://www.cibersociedad.net/textos/articulo.php?art=24, última consulta el07/07/2013].

-- (2003): "La llengua catalana en la comunicació a Internet: questió de codis", Llengua i ús 26, pp. 77-82.

[http://www6.gencat.cat/llengcat/liu/26_139.pdf, última consulta el 13/12/2013].

Yus, Francisco (2001a): Ciberpragmática. Barcelona: Ariel.

-- (2001b): "Ciberpragmática: entre la compensación y el desconcierto". Presentado en el II Congreso Internacional de la Lengua Española. El Español en la Sociedad de la Información. Valladolid [http://congresosdelalengua.es/valladolid/ponencias/nuevas_fronteras_del_espanol/4_lengua_y_escrit ura/yus_f.htm, última consulta el 13/12/2013]. 